\section{Quantification of Abdominal Aortic Aneurysm Calcification Using the Agatston Method Can Predict Accelerated Expansion Rate}

\author{
Atsuko Nakayama, MD, PhD; \\ Hiroyuki Morita, MD, PhD; \\ Katsuyuki Hoshina, MD, PhD; \\ Issei Komuro, MD, $\mathrm{PhD}$
}

$\mathbf{W}$

e recently reported that calcification index $<2.74 \%$ is a good predictor for the accelerated expansion of abdominal aortic aneurysm (AAA), ${ }^{1}$ but it is not easy to put this into practice because of the requirement for manual plotting on the reconstructed volume-rendered AAA images (Figure A,C). Simpler evaluation of AAA calcification should facilitate its practical use. Here, we explored whether the Agatston method, established as a simple and accurate quantification of calcification in coronary arteries, ${ }^{2}$ could be used for the measurement of AAA calcification. After setting both ends of all AAA $(n=414)$ in the same manner as our previous study, ${ }^{1}$ Agatston score and AAA calcification volume were automatically calculated with the Agatston method using 3D Slicer (Figure B,D). The study was approved by the Ethics Committee of the University of Tokyo Hospital. The calcification index was significantly correlated with Agatston score and with calcification volume $(\mathrm{R}=0.525$, $\mathrm{P}<0.001$, and $\mathrm{R}=0.531, \mathrm{P}<0.001$, respectively). According to the area under the receiver operating characteristic (ROC) curve for predicting accelerated AAA expansion ( $>5 \mathrm{~mm} /$ year), Agatston score and AAA calcification volume could be significant markers for AAA expansion $(\mathrm{P}=0.016$ and $\mathrm{P}=0.004$, respectively; Figure $\mathrm{E})$. AAA Agatston score $<1,181$, corresponding to the inflection point of the ROC curve, was the optimal cut-off, having a sensitivity of $66 \%$ and specificity of $55 \%$. Even after adjusting for age $>65$ years, sex, body mass index $>25 \mathrm{~kg} / \mathrm{m}^{2}$, hypertension, dyslipidemia, diabetes, ex-smoking, current smoking, past history of chronic obstructive pulmonary disease, and statin use, AAA Agatston score $<1,181$ remained a significant predictor of accelerated AAA expansion $>5 \mathrm{~mm} /$ year (hazard ratio, $2.920 ; 95 \%$ CI: 1.474 5.788, $\mathrm{P}=0.002$ ). In conclusion, the Agatston method can be used to evaluate AAA calcification and hence predict AAA expansion.

Received May 17, 2018; revised manuscript received June 14, 2018; accepted July 17, 2018; J-STAGE Advance Publication released online August 31, 2018 Time for primary review: 26 days

Department of Cardiovascular Medicine (A.N., H.M., I.K.), Division of Vascular Surgery, Department of Surgery (K.H.), Graduate School of Medicine, The University of Tokyo, Tokyo, Japan

Mailing address: Atsuko Nakayama, MD, PhD and Hiroyuki Morita, $\mathrm{MD}, \mathrm{PhD}$, Department of Cardiovascular Medicine, Graduate School of Medicine, The University of Tokyo, 7-3-1 Hongo, Bunkyo-ku, Tokyo 113-8655, Japan. E-mail: st7089-fki@umin. ac.jp; hmrt-tky@umin.net

ISSN-1346-9843 All rights are reserved to the Japanese Circulation Society. For permissions, please e-mail: cj@j-circ.or.jp

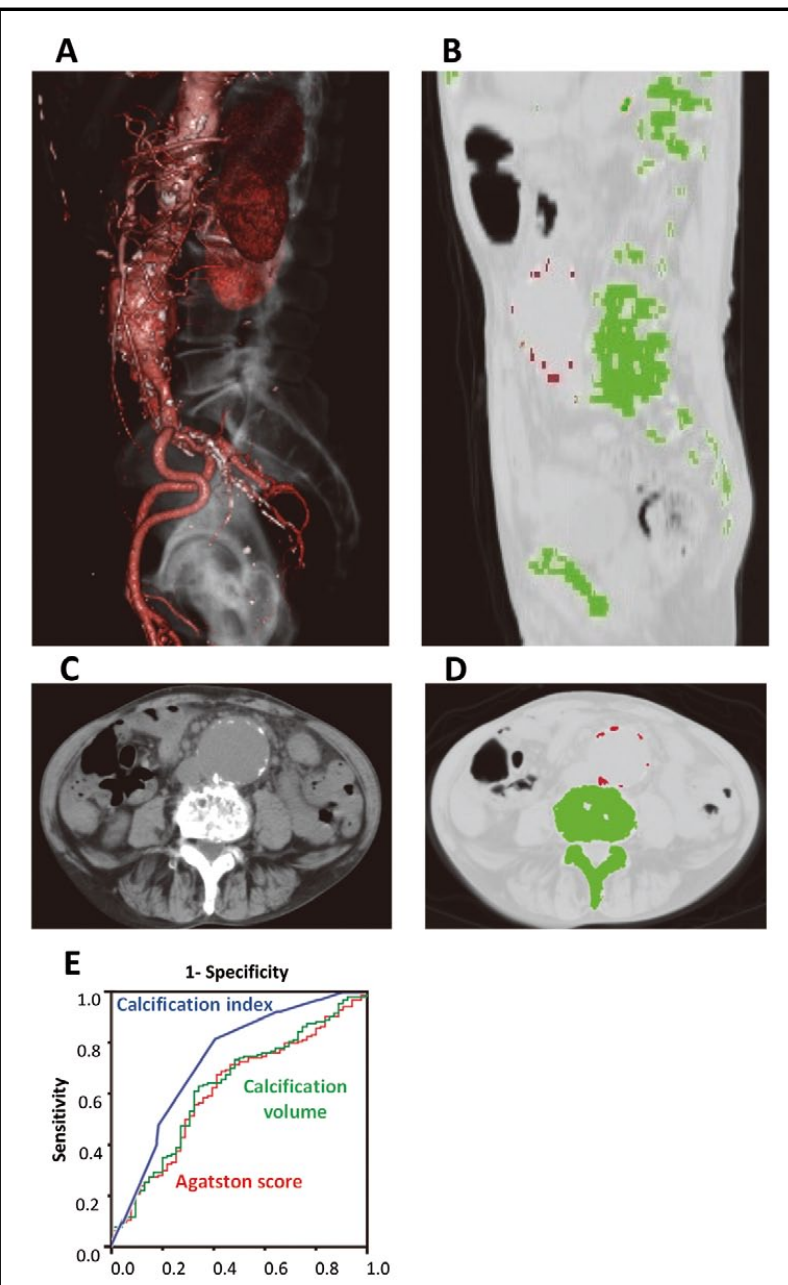

Figure. Calculation of abdominal aortic aneurysm (AAA) calcification. (A) 3-D volume rendering method (axial view). (B) Agatston method (axial view). Red area in aortic wall, region of interest of calcification $(>130 \mathrm{HU})$ with any Agatston score. Green area, bone. (C) Volume-rendering method (horizontal view) to reconstruct contiguous 5-mm thick transverse computed tomography AAA slices. (D) Agatston method (horizontal view). (E) Receiver operating characteristic (ROC) curve for predicting accelerated AAA expansion ( $>5 \mathrm{~mm} /$ year). Area under the ROC curve was as follows: calcification index, $0.73(\mathrm{P}<0.001)$; Agatston score, 0.604 $(P=0.016)$; and calcification volume, $0.623(P=0.004)$.

\section{Acknowledgments}

This work was supported by a Grant-in-Aid from Okinaka Memorial Institute for Medical Research.

\section{Disclosures}

The authors declare no conflicts of interest.

\section{References}

1. Nakayama A, Morita H, Hayashi N, Nomura Y, Hoshina K, Shigematsu K, et al. Inverse correlation between calcium accumulation and the expansion rate of abdominal aortic aneurysms. Circ J 2016; 80: 332-339.

2. Agatston AS, Janowitz WR, Hildner FJ, Zusmer NR, Viamonte M Jr, Detrano R. Quantification of coronary artery calcium using ultrafast computed tomography. J Am Coll Cardiol 1990; 15: $827-832$. 